\title{
Opportunities of Usage: Reflection on Subject and Space in Psychotherapy
}

\begin{abstract}
The article presents an interdisciplinary analysis of possible object's usage in psychotherapy of adults. It is also focused on the meaning of the area where psychotherapy takes place. The text presents multidimensional view on psychotherapy, which is understood not just as psychological but also socio-cultural phenomenon. The article indicates also a "turn toward the thing" in contemporary humanistic and social studies. Material base of psychotherapy is very important in establishing (crucial for positive impact of psychotherapy) good enough therapeutic relation. Theoretical reflections which bind cultural studies and psychological perspective are crowned by case study of family therapy in which objects and place of therapy were important elements of therapeutic process.
\end{abstract}

\section{Keywords:}

object, psychotherapy, therapeutic relation, therapy in patient’s house

1 Department of the Semiotics of Culture, Institute of Cultural Studies, Faculty of Social Sciences, Adam Mickiewicz University in Poznań, marcelak@amu.edu.pl/. The abstract was translated by the author, the text was translated by Marita Kaczmarek. 


\section{INTRODUCTION}

For many years, objects have been used in various therapeutic approaches as tools supporting psychotherapeutic, or often artetherapeutic, work. Pillows or empty chairs are used as aids in systemic and gestalt therapy. This paper, however, focuses on a different use of the awareness of objects which coexist in patient's and therapist's surroundings in every form of therapy.

Using the awareness related to therapeutic surroundings may be a way to establish a therapeutic alliance or to deepen a therapeutic relationship, and lack of such awareness may cause difficulties in keeping close bonds.

\section{THERAPEUTIC RELATIONSHIP}

The issue of creating a relationship between the person who wants a change and the professional who supports the process is highly relevant to achieve the positive effects of therapeutic work. Numerous studies on the effectiveness of psychotherapy have shown the enormous influence of the so-called nonspecific factors (that are unrelated to techniques attributed to certain therapeutic schools or approaches) in the process of achieving therapy purposes and patient healing (Rakowska, 2006; Critelli, Neumann, 1984; Froyd, Lambert, Froyd, 1996; Howard, Kopta, Orlinsky, 1986). Establishing a therapeutic relationship requires not only competences and psychological knowledge or abilities closely related to the skills of working in accordance with certain therapeutic approaches. Building a positive therapeutic relationship to a large extent depends on therapist's social and cultural competences. For this reason, the issue needs to be analysed both from the psychological and the cultural side.

With reference to hermeneutic perspective (Gadamer, 2013), it may be indicated that both the therapist and their patient are individuals who have certain beliefs concerning the therapy (the so-called presumptions), certain memories and social behavior patterns, and the meeting of the therapist and the patient is also the point where these two areas of experience come into contact. Using another element, that is an object, may be helpful in order to establish a common ground and safety in therapy. In fact, this third element always accompanies the process of therapy, which has its material basis. Rarely is the problematization of psychotherapy surroundings addressed (one of the exceptions is the analysis of using the realistic grasp of an object in the therapy of psychotic disorders [Prouty, 1994, pp. 73-75]). It may appear, however, that especially nowadays, with 
a deluge of consumer objects affecting social isolation, the objects that accompany interpersonal relations (and strengthen them) become very important. Not only do existential therapists acknowledge the importance of the material dimension of interpersonal gift (Barnett, Madison, 2012). Lacanian psychoanalysts, who provide therapy taking particular account of linguistic phenomena, determine different understanding of the object in Freud's works and in the present cultural situation, in the era of capitalism. It is pointed by Jacques Borie (unpublished lecture, 2015), interpreting Lacan's late works, who says that psychoanalysis must read the changing social reality and notice that the wishes of the people of today do not belong to them anymore, but are continually provided to them, created by the mechanisms of the capitalist reality. At the same time, however, Borie notices differences between the two types of objects. Type one are impulse objects, closely related to the human body (for example, breasts or nipples for a child who is in relation with their mother); they are directly linked to an interpersonal relation, being kind of a gift within the relation (where the other party may offer intimacy, touch, presence, also in the material sense). The other class of objects are those that, having purely consumption value, are empty inside, not carrying any other idea except for the one that is connected without reproduction.

The paper's perspective provides for the possibility of renewing social relationships by referring to the object which constitutes kind of a gift in the relationship. Data from the attempts of space analysis in therapy and references to the shift to objects, which is present in contemporary humanities, were used to analyze the phenomenon of the object used for the relationships.

In his book entitled "In Defense of Things", Bjonar Olsen (2013) quotes the analyst of Icelandic texts who minds that objects are not poor substitutes for relationships, but they exist at the heart of every interpersonal contact. Friendships, loves and other relationships are also of object-related nature, happening in the world where objects are present, being the integral part of life. Experiencing a relationship with objects allows for regaining reality and establishing intrapsychic and interpersonal contact in line with reality principle, which is of key importance in the context of communicating with a person who suffers from mental disorder or experiences crisis situations. In addition, for a patient with interpersonal problems, relationships with objects are often easier than relationships with other human beings, and this is why paying close attention to contact with surroundings may be an area of experiencing safety and of the reduction of tension for the patient. 


\section{CULTURE STUDIES PERSPECTIVE}

The observation of changes in contemporary humanities may be of great importance for clinical practice or a specific psychotherapeutic perspective. Patients participating in the process of therapy are not disconnected from the culture in which they have been socialized. Their current situation is also dependent on the whole present life context, they are part of the complex network of relationships that surround them and that are co-created by them. Thus a broader social and cultural context is worth being included in the reflection upon the patient's problem.

Many therapeutic schools use the postmodern concept to create new basic conclusions for working with patients. They have recognised the need to combine philosophical, sociological, or culture studies-related thoughts and psychotherapeutic thinking. The assumptions incorporating cultural context in therapist's work include, inter alia, adopting cultural relativism, deriving from social constructivist thought, conviction about the importance of pluralisation and multiplication of points of view on a given problem (currently especially in couple and family therapy; see Andersen, 1987; Fee, 2000; Chrząstowski, de Barbaro, 2011).

In addition to many precious values that have been contributed by the contemporary thought of postmodern humanities, appreciating individuals and indicating the importance of acceptance for each of the alternative ways of thinking, postmodernism (or some of its aspects) also brings a great load of nihilism and separation from the material realities. What underpins the postmodernist thinking is the destruction of central, applicable theories that are intended to be universal. Referring to Kant's reasoning (2001) related to the impossibility to reach noumena (or things-in-themselves), some postmodernists have radicalized theses about the end of representation and depleted relations between the reality and its references. Jean Baudrillard (2005), considered to be one of the main theoreticians of postmodernist thinking, developed the concept of the precession of simulacra. Here the diagnosis of the social reality is related to the conviction about the lack of access to the originals, to the reality, and the action of multiplying endless copies of other copies, or memories, of the reality. Referring to clinical practice, it may be pointed out that, in fact, such duplication of memories occurs in some disorders, especially in those connected with posttraumatic stress. However, it also raises questions about whether total trust in the concept which, after all, causes suffering in people who are affected by the consequences of trauma, would result in therapeutic effectiveness.

It might be more accurate to acknowledge the value of Baudrillard's structure for patient's or group's diagnosis, and at the same time further seeking for con- 
nections to reality. This is the path taken by authors involved in the trend of new materialism, or "back to the things" approach. Their ideas seem to rather develop the arguments of postmodernism than be the return to essential concepts. They appreciate individuality, individual perspective and differences, but they also point out to the necessity of rethinking the relationship of human beings with the reality and the type of conceptualization of this relationship. As Rosi Braidotti (2012), one of this approach's representatives, states - one should not confuse new materialism with sanctifying matter or its pure, social shaping. The trend treats objects as mobile entities closely related to the perspective of action. This is where Krzysztof Arbiszewski (2005) mentions relations ontology, where we do not return to the essential focus on the essence of the matter, but we rather study the essence of relation between things. Bruno Latour, the theoretician to whom Arbiszewski refers, creates Actor-Network Theory (ANT), where every object is relevant as a partner for cooperation or even communication. Latour indicates that interpersonal communication takes place within certain frameworks and that it is, to a greater or lesser extent, mediated. Phone calls, using the Internet, but also face-to-face meetings require a certain physical space and a material context of reference. Here objects are not only a background for a conversation of two people, but they play an important role in it. Translated into the context of psychotherapy, it may show how important the stability of the place and time of therapy is for some therapeutic schools. Therapeutic setting, so important for psychoanalysis and in psychodynamic trends, refers to the space which gives safety to the patient (especially in the first phase of therapy). Whereas minor changes in the office introduced during the therapy may accentuate transformations on the background of the unchanging landscape, not only mirroring the process of development and change, but also constituting a sign of the reality of the changes that are not only of inside-the-psyche nature (as in patient's life). Therapist's office is the place of forming diverse relationships with oneself and other people, but also with the whole surroundings, and the space of contact between the therapist and the patient becomes also the place of relationships with another person's sensitivity.

In order to develop this argument and identify its cultural sources, one may refer to Susan Sontag's idea, as a matter of fact parallel to postmodernist concepts, which was based on the scientific interpretation of objects which are works of art; instead suggesting turning to feeling, sensuous contact with images and objects, and treating the latter as individual artifacts and not the metaphors of something else. The analysis of the author's diaries shows that her ideas are close to contemporary new materialism. But, importantly for this paper, Sontag's remarks related to experiencing art may be virtually directly translated into the context 
of therapeutic relationship. Describing her experiences of contact with paintings, the essayist notices not only their content or form (in fact she goes beyond these categories), but she also focuses on the very materiality of the works. "Canvas is needed because colors cannot float in the air,” she says (Sontag, 2013, p. 91). This seemingly trivial statement may prove to be extremely important in contact with patients suffering from dissociation or psychotic states. For Sontag, contact with the reality of objects becomes the basis of her editorial choices. Designing covers of subsequent books, she selects independently the images that are supposed to attract viewer's attention. She is guided by her intuition and the emotional message of the object - a painting or a sculpture. Commenting on the choice of the cover for an extremely strongly related to her own experiences book entitled "Illness as Metaphor" (written when Sontag was going through cancer), the author says, "There is some sensuous beauty in the male figure depicted on the image. I believe that our reactions are so sensual and ultimately kinetic” (Sontag, 2014, p. 39).

Senses and movement, appreciated by Sontag, are strictly connected with the physiological reactions of organism, coupled together with the activation of emotion mechanisms (Le Doux, 2000, p. 47, 49). Modern neuroscience confirms that contact with art and experiencing art with senses is conducive to the activation of many brain centres, and even has an effect on the activation of neurogenesis, which is associated with the formation and maturation of new neurons in the hippocampus (Wojnar, 2014; Jedynak, Jahołkowski, Filipkowski, 2007).

Neurogenesis is still a relatively little explored phenomenon, but we know with certainty that it is of great importance in repairing brain damage, and possibly also facilitating the acquisition of new abilities (learning). In addition to aesthetic experiences, residing in a diverse environment is also an important factor favoring neurogenesis. Therapy may be understood not only metaphorically, but in some cases also practically, as experiencing a diverse environment (it is often the case for senior patients, people with anxiety disorders, for whom getting to the therapist is a problem, but at the same time it is an opportunity to overcome it, and for people suffering from depression, who break their stagnancy and reluctance to take on challenges by deciding to visit therapist's office). In psychotherapeutic literature, one may often read about various attempts to break patient's resistance to change or about taking therapeutic action. It seems, however, that for patients in deep crisis, for whom the very getting to the meeting, in the physical sense, is difficult, the act may be perceived as an extremely relevant factor of change, not only at the decision level, but also at the level of its real execution. In case of other patients, it is not the warm tone of therapist's voice, but the order and symmetry present in the office that is the first element supporting the process of therapy. 
One of the examples are Asperger syndrome patients. Christine Preißmann, who wrote a book on the aforementioned disorder (2012), psychotherapist and doctor, diagnosed with Asperger syndrome, devotes part of her handbook for therapists and parents of people suffering from the disorder, to the issue of therapist's office's appearance (Preißmann, 2012, pp. 54-56). In her book, she indicates that it was the room where her own therapy was conducted that had a decisive influence on the positive result of the therapy. She says that chaos in therapist's office would be such a major impediment for her that it would prevent her participation in therapy. Visible and perfect order creates the sense of security in people with Asperger syndrome. When working with people suffering from this disorder, it is also worth ensuring that there are not too many distracting objects in the office, which could attract patient's attention more than the relationship with the therapist. Asperger syndrome seems to be a disorder that shows how important objects may be in our lives. Their presence is very predictable (until they have been rearranged by somebody). They may be a kind of metaphor for the stability of the acceptance that may be experienced by the patient in therapist's office. But it is also a space of challenges related to human activity.

\section{CASE STUDY: HOME AS THERAPY SPACE, USE OF HOME SETTING - ADVANTAGES AND LIMITATIONS}

The previous paragraph emphasised the role of space consistency of a neutral therapist's office, considered as a safe area for a person in therapy. However, different spaces can also become a therapy space - a hospital, a homeless shelter, or the apartment of a person going through a psychic crisis. Below, there is a case study of a family whose therapy was conducted in their home. The daily living space became also a therapy space, the one where the presence of objects and specific space was more thoroughly analysed by the therapist and the supervision group.

Since specific circumstances made it difficult for the family who decided to go into therapy to attend meetings at therapist's office, sessions took place at the family's home, which had both a positive and negative impact on the systemic therapy. Having familiarised herself with different approaches to home therapy, the therapist ${ }^{2}$ was aware that this would be a very specific work. A therapist entering patient's home might feel like a guest - not more important than their host (although they may also be perceived as an unwanted guest or an intruder, as it

\footnotetext{
2 The author of the article.
} 
often occurred during therapy sessions with families whose members were not unanimous in wanting to go into therapy). It is also not possible for a therapist conducting a session in this kind of setting to create an atmosphere of safety through a neutral surrounding and small changes in the office which emphasise the change in patient's life.

On the other hand, this was the only chance for the therapist to meet with all the members of the family and to experience directly the reality of this family's everyday life. In the course of examining advantages and limitations of home therapy, a study was found: it summarised the experience of home therapists working in rural environments in northern parts of New England (Day, McCain, Victoria, 1999). The results of this study proved that as much as that kind of therapy is not more efficient than office sessions, it gives access to therapy to people who would otherwise not be able to participate in it. There are also positive results of the use of environmental support where the therapists visit their patients, and not vice versa. The most efficient form of this kind of interventions is the open dialogue method created in Finland by Jaakko Seikkula and his team (Seikkula, Olson, 2003). The authors of this conception applied this method of therapy in the environment of a person who was going through the first psychotic episode and the results achieved during a 2-year-period of monitoring this therapeutic process were far better than those obtained through conventional methods of treating psychotic episodes. It appeared that only in 35\% of cases further treatment with neuroleptics was required and the condition of $82 \%$ of patients participating in the programme improved to a point where they could lead a normal life in their communities and presented few or no symptoms. This therapy method is based on the cooperation of a reflective team and of the entire local community, whom the support group meets in their place of residence. The idea is not to isolate but to reintegrate the patient with their local community. The author of this article also had the opportunity to meet the family in their original environment. At times, members of the family who no longer lived in the family house would also join in (adult children) as guests visiting the therapy space. This was always an important source of reference, which would enrich knowledge on the entire family system.

The patient identified was a person with moderate intellectual disability and the goal of this therapy (established in the course of several sessions) was to improve communication between family members: two brothers (one with disability) and the wife of one of the brothers and sister-in-law of the other. The therapy was not static, but involved the entire domestic space which the family members would fight for when the conflict escalated and share during moments of peace and respite. Whenever they were able to communicate and understand the mechanisms of 
conflict, the dining room space, where the therapy took place, would really become a shared space. In those moments a true sense of community and unity would appear, and the identified patient, who previously felt excluded from the domestic community, would harmoniously join the conversation and share domestic equipment (also the TV set, which now became identified as belonging to everyone, even though the person with disability had another TV set in a symbolically isolated room). All members of the family, visibly calmed by the perspective of sharing goods, perceived those conversations as a way to bring back the balance that was lost due to many conflicts. In the course of therapy it also became apparent that the identified patient would withdraw into his room whenever the situation got too difficult for him to handle emotionally (after demonstrating his power by expressing anger). This was a more apparent form of a behaviour each member of the family would demonstrate. As much as they longed for unity, each one of them created their own sub-system, with a separate refuge and isolation space rather than a shelter. Therefore, it turned out that the inner boundaries of this family system were rather stiff. Mrs R. would flee to the kitchen, whereas her husband valued the recreational plot, which also became a space that was an alternative for therapy. In the course of therapy the family gained a greater awareness of the fact that even though they did value the community of space and contact, which was also a source of family bonding, given the communication difficulties and personal suffering resulting from disability, they all needed a personal respite space where they could escape from the challenges of everyday life. Therapy also strengthened the marital dyad, which made the couple see the difference between the family community and control within the family. Unfortunately, in moments of personal crisis, each of the family members would return to old reaction schemes and beliefs on the hopelessness of their situation.

The therapy lasted six months, sessions took place once a week and lasted 1 hour and 30 minutes each. The identified patient would often perceive me as an intruder in his home and private space, which was the greatest ethical dilemma. However, the patient's behaviour was not consistent. He would first express his great disapproval and order the therapist to leave the apartment. But at the same time he did not mind the therapist visiting him in his room, as if he only objected to the fact that she would come to see his brother and sister-in-law "in his case" (as he saw it). Whenever this happened, we would specify and emphasise the goal of the therapy and the fact that the therapist came to the house to help the entire family to communicate better - as it was established before (with him). During the parts of the sessions which took place in the identified patient's room, the therapy was rather non-standard - the therapist would watch TV with the patient and build 
a therapeutic relation from there. Apart from the TV set, another important element in the patient's room were his sports trophies. Metaphors related to sports or TV series were used to analyse the meaning of independence and the need for presence of another person and of a family community. The need to express his proactivity clashed with the man's need to cooperate with other family members, whom he believed to be overly controlling and not respectful of his independence and the values he believed in. Although with great difficulty (resulting also from past experience of this family), the views and values of other members of the family were respected for a certain period of time and common ground was found (such as love for sports, mutual care and will to help each other, essential qualities founding family community). Since the therapy was taking place in the family's home and the therapist had the chance to understand the identified patient's values and interests, a relation with the patient was established much faster. The proof of high quality of therapeutic relations was that the patient cared for the therapist and expressed it by giving her presents he made himself. However, towards the end of the therapeutic process, the identified patient (probably due to the escalation of the family conflict) once more started to perceive the therapist as an enemy and the couple decided they needed time from therapy off to spend at the recreational plot. Thus, the success of the therapy can only be called partial, yet it is not automatically a failure (since the goal was not to eliminate conflicts, but to improve communication and negotiation skills of all family members so that they can achieve their personal goals, while respecting the needs of others).

Perhaps the neutral space of therapist's office would allow all family members to get more involved, but this would require forcing one or two members of this small community. The fact that the therapist was also a guest made all the family members feel stronger and more proactive than they would feel during a session in the office. This allowed the therapist to discover the family's resources and to begin working with them much faster and more effectively. The change that happened during this time also considered their everyday life space, which seemed to be of particular importance for the identified patient to whom the sessions gave the opportunity to see himself in a very different light. He acted like the raconteur he usually is in other settings, such as workshop therapy sessions or the park. Soon enough his stories came to dominate the discussion and attempts at bringing back balance resulted in him falling back into the belief that people with disabilities are always ignored and blamed for something. Certainly, a long time experience of many difficulties and forms of exclusion must have contributed to the wariness demonstrated by one of the brothers and to the frustration of the entire family. It was not possible to achieve a durable change in such a short period of time (six 
months), but the entire family began to see their roles in a different light. Furniture, previously used also as symbols of domination, has lost its "magic" power and became, again, just elements of the context.

What came to prove the success of the therapy (at least partial) was that even though at the beginning of the therapeutic process one of the spouses ordered the disabled brother to sit on only one of the chairs, by the end each person could choose the space he or she liked best. Thus the identified patient would sometimes stand, walk from place to place or sit on different chairs. The lack of comments on this type of behaviour was a sign of a greater acceptance of the identified patient's different lifestyle, who loved walking around the city or wandering around for hours, with no specific destination in mind. Home objects were initially obstacles in contacts, but thanks to the open attitude on both sides, their role has changed. Paradoxically, it was often the TV that facilitated contact. The seemingly distracting gear which the identified patient would use to lower tension and draw attention away from his behaviour soon became an element of a metaphor which was a starting point to discuss real problems. By recalling the TV programme, the patient would signal that he was at a breaking point during an emotionally challenging conversation.

While maintaining the principle of optimum difference introduced to family and system therapy by Tom Anderson (in: de Barbaro, 2007), the therapist tried to lead the conversation in a way that expressed interest in the patient's hobbies and ways of coping with difficulties, while trying to induce change. Direct communication would stress the patient, therefore a communication model involving metaphors (invented by the patient, deriving from soap operas) was elaborated. The multitude of interacting plots brought by the silver screen could be used to describe real life relations with friends and family. At times the patient would want a more natural conversation and too much attention given to one prop (glasses he did not want to wear before) made him suspicious and disrupt the carefully established relation. The difficulties show how challenging therapist's work is when the surrounding objects play such an important role. They are props, they guarantee safety, but there is also a risk that a visibly evident symbol will be perceived as deception, a trick, not a sign of authentic contact. The second risk area is the loss of bond and going from a dialogue to two monadic monologues which focus only on consumer value of the surrounding objects. This was not the case of the family described above, but choosing separate personal domination zones could have had the same purpose - isolation that provides each ruler of a small space with the feeling of safety and proactivity. For each member of the family, the possibility of establishing such a small domination zone had a positive influence on the homeostasis of the entire system. 


\section{CONCLUSIONS}

The heritage of contemporary human sciences emphasises both the main aches and pains of contemporary western societies and their main needs. Psychotherapy that is susceptible to cultural knowledge can (at least to a degree) respond to the challenges of contemporary individuals and systems.

Being aware of the environmental impact is crucial in establishing a positive therapeutic relation that is necessary for a therapy to be successful. The analysis of reference to objects may pinpoint many diagnostically important elements of the therapy process and be a reference point for creating individualised methods of therapeutic work. Realising the importance of a realistic therapy setting is particularly important when dealing with people on the autism spectrum or people experiencing psychotic episodes. When working with systems, the analysis of interactions of family or group members with the surrounding objects may be a source of information on the level of stress in family members, on the limits of the system, or on the defence mechanisms chosen by patients. Creative use of space and objects may be a key element of patient's evolution process, also in a neurobiological sense (through neurogenesis).

\section{References:}

Andersen, T. (1987). The reflecting team: dialogue and meta-dialogue in clinical work. Family Process, 26 (4), 415-428.

Baudrillard, J. (2005). Symulakry i symulacja. Warszawa: sic!

Borie, J. (2015). [unpublished lecture „Jouissance. The Power of Objects”, Poznań, January 19].

Chrząstowski, Sz., \& de Barbaro, B. (2011). Postmodernistyczne inspiracje w psychoterapii. Kraków: Wydawnictwo Uniwersytetu Jagiellońskiego.

Critelli, J.W., Neumann, K.F. (1984). The placebo. Conceptual analysis of a construct in transition. American Psychologist, 39 (1), 32-39.

Day, H., McCain, D., Victoria, M. (1999). Values held by office-based therapists and home-based therapists in Northern New England. Counseling and Values, 43 (2), 116-128. DOI: 10.1002/j.2161-007X.1999.tb00134.x

de Barbaro, B. (2007). Po co psychoterapii postmodernizm. Psychoterapia, 3 (142), 5-14.

Fee, D. (2000). Pathology and the postmodern. Mental illness as discourse and experience. London, Thousand Oaks, New Delhi: Sage.

Froyd, J.E., Lambert, J.D., \& Froyd, J.D. (1996). A review of practices of psychotherapy outcome measurement. Journal of Mental Health, 5 (1), 11-16.

Howard, K.I., Kopta, S.M., Krause, M.S., Orlinsky, D.E. (1986). The dose-effect relationship in psychotherapy. American Psychologist, 41 (2), 159-164. 
Jedynak, P., Jahołkowski, P., Filipkowski, R. (2007). Neurogeneza dorosłych a depresja. Neuropsychiatria i neuropsychologia, 2 (2), 57-65.

Kant, I. (2001). Krytyka czystego rozumu. Kęty: Antyk.

Le Doux, J. (2000). Mózg emocjonalny. Poznań: Media Rodzina.

Olsen, B. (2013). W obronie rzeczy. Archeologia i ontologia przedmiotów. Warszawa: Wydawnictwo Instytutu Badań Literackich.

Preißmann, Ch. (2012). Zespół Aspergera. Jak z nim żyć? Jak pomagać? Jak prowadzić terapię? Sopot: Gdańskie Wydawnictwo Psychologiczne.

Rakowska, J.M. (2006). Skuteczność psychoterapii. Warszawa: Scholar.

Seikkula, J., Olson, M.E. (2003). The open dialogue approach to acute psychosis: its poetics and micropolitics. Family Process, 42 (3), 403-418.

Sontag, S. (2013). Jak świadomość zwiqzzana jest z ciałem. Pisma zebrane, vol. II. Warszawa: Karakter.

Sontag, S., Cott, J. (2014). Myśl to forma odczuwania. Warszawa: Karakter.

Wojnar, A. (2014). Badania nad mózgiem. Retrieved from: http://www2.almamater.uj.edu. $\mathrm{pl} / 114 / 15$. 